\title{
Comment on Moverley et al.: Impact factors of orthopaedic journals between 2000 and 2010: trends and comparisons with other surgical specialities
}

\author{
Julio Urrutia
}

Received: 15 February 2013 / Accepted: 23 April 2013 / Published online: 23 May 2013

(C) Springer-Verlag Berlin Heidelberg 2013

\section{Dear Editor,}

I read with interest the article "Impact factors of orthopaedic journals between 2000 and 2010: trends and comparisons with other surgical specialties" by Moverley et al. [1]. I think that the article provides useful information about the trends of citations in the orthopaedic literature. However, there are some inaccuracies that are worthy of mention.

First, the Journal of Orthopaedic Science is the official journal of the Japanese Orthopaedic Association, and it is published by Springer, so it should not be considered as "published in the US" as is shown in Table 1. Furthermore, the European Spine Journal cannot be considered as "published in the US" either (also shown in Table 1).

In addition, the authors did not include the Journal of Spinal Disorders \& Techniques among the specialist orthopaedic journals. Most orthopaedic surgeons would agree that the Journal of Spinal Disorders \& Techniques is an important source of information for most orthopaedic surgeons working in the spine field, and certainly it should be considered an orthopaedic journal.
Since the authors compared the impact factor of journals published in the USA to journals published in Europe, these flaws affect their results, and they could affect their conclusions.

Sincerely, Dr. Julio Urrutia

Chairman, Department of Orthopaedic Surgery

School of Medicine, Pontificia Universidad Catolica de Chile

\section{Reference}

1. Moverley R, Rankin KS, McNamara I, Davidson DJ, Reed M, Sprowson AP (2013) Impact factors of orthopaedic journals between 2000 and 2010: trends and comparisons with other surgical specialties. Int Orthop 37(4):561-567
J. Urrutia $(\bowtie)$

Department of Orthopaedic Surgery, School of Medicine, Pontificia Universidad Catolica de Chile, Santiago, Chile e-mail: jurrutia@med.puc.cl 